\title{
Development of Micro Grid model for Stability Assessment
}

\author{
I. Vokony, A. Faludi, A. Dán \\ Dept. of Electric Power Engineering, Group of Power Systems and Environment \\ Faculty of Electrical Engineering, Budapest University of Technology and Economics \\ 18 Egry József Street, Budapest, 1111 Hungary \\ Phone: +36/30/640-90-13, e-mail: vokony.istvan@,vet.bme.hu
}

\begin{abstract}
This paper is qualified for the assessment of cooperation and interaction of micro grids (furthermore referred to as $\mathrm{MG}$ that means a micro network with about zero transfer power) and power system (furthermore referred to as PS that means the connection and synchronous operation of each generators and consumer districts through the electric network). Primarily it examines the effect of the continuously increasing integration of the intelligent energy distribution networks concerning the stability of the PS. In the paper the model is published, used for simulating the MGs and how to apply them for stability assessment. With the help of a model network the results of the simulations are presented and also the conclusions can be drawn are evaluated. The expectation is that the stability of the PS will increase in consequence of the growing number of the MGs.
\end{abstract}

\section{Keywords}

Micro grid (MG), power system (PS), power balance, stability, time-domain simulation

\section{Introduction}

The history of development of the PS everywhere proceeded through similar phases: the initially local supply was followed by transfers of shorter distance and finally national interconnected networks came into operation. These networks were connected for the sake of mutual technical help and nowadays the networks are used for great commercial transports as well covering whole Europe. This global PS definitely has many advantages, but nowadays its disadvantages come increasingly into foreground. Because of the high level of loading of system elements, the reliability of supply is decreasing, provided by some recently recorded cases.

Those kinds of network structures are needed to be established, the direction of which are more favorable and designable. They simplify the system, - from the system regulation's point of view - are able for island operation and in some cases they can join the PS. The MG can be a solution for the above questions. On the other hand for the examination of these kinds of micro networks the creation of a suitable model is essential.

\section{Model Development}

To develop the model network it was necessary to have a looped system model, containing the typical elements of the high voltage systems. (E.g.: different voltage levels busses $(400 \mathrm{kV}, 220 \mathrm{kV}, 120 \mathrm{kV}$, etc.), transformers, parallel wires, loads, and generations). Into the developed looped say conventional network model a so-called MG is assimilating consisting of a generator and loads. This generator works on $6.3 \mathrm{kV}$ voltage level and supplies the connecting loads. In this case this MG is a self-supplier grid, which is able to work in island operation.

After developing the network topology we had to model the generators completing the expectations. 


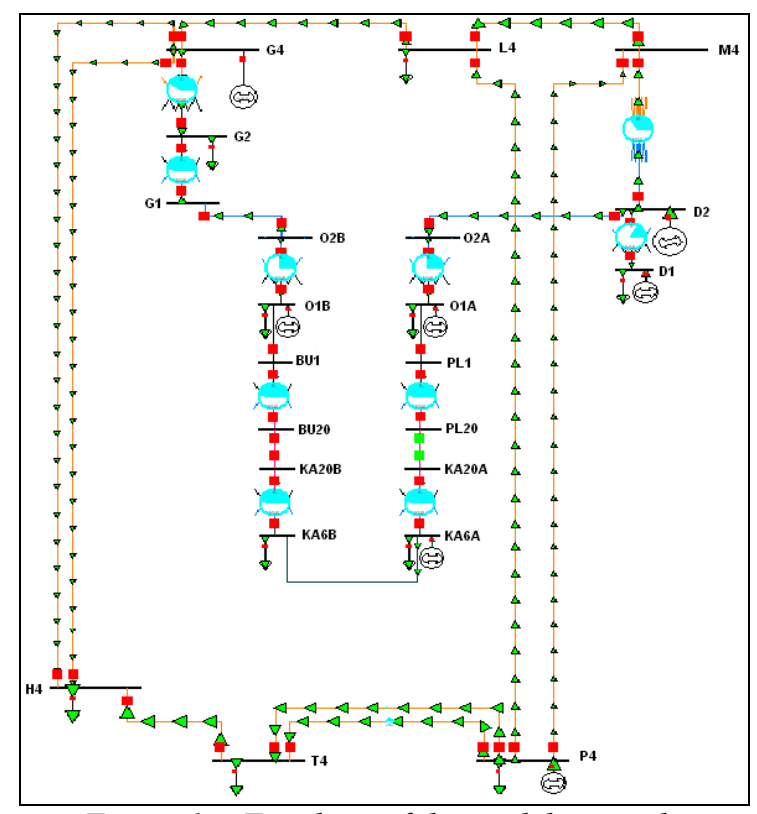

Figure 1.: Topology of the model network

The generators are modeled in the simulator with a synchronous spinning d-q co-ordinate system sub transient model. The excitation controller is a static controller, and the turbine controller is a simplified, frequency-sensitive controller with $5 \%$ statism. Our aim was to make two independent loading points to the MG. There is no under-loop in the model network, it means, that the network is radial in lower voltage levels.

We can separate the analysis into two groups by the aim: first of all we wanted to analyze how the network affect to the MG, on the other hand the effect of MGs hopefully robustness increasing -to the network.

\section{Simulations}

The simulated fault is the following: 3 phase sc. on the line close to the bus lasting $0.3 \mathrm{sec}$, than the faulted line is switched off. The program is able to save the results in a separated file, and its changes. Selected electrical parameters can be stored as well.

The analyzed parameters:

- generators load,

- bus voltages,

- frequency,

- turbine load,

- sc. currents.

The simulated faults are resumed in table 1 .

\begin{tabular}{|c|c|c|c|c|c|}
\hline place of fault & type of fault & faults long [sec] & sc. current [kA] & KA6A gen. $\mathrm{i} / \mathrm{o}$ & comment \\
\hline G4 & $3 F$ & 0.3 & 9.5 & $\mathbf{i}$ & - \\
\hline $\mathrm{H} 4$ & $3 F$ & 0.3 & 8.6 & $\mathbf{i}$ & - \\
\hline M4 & $3 F$ & 0.3 & 8.6 & $i$ & - \\
\hline $\mathbf{L} 4$ & $3 F$ & 0.3 & 8.2 & $\mathbf{i}$ & - \\
\hline T4 & $3 F$ & 0.3 & 9.8 & $\mathbf{i}$ & - \\
\hline P4 & $3 F$ & 0.3 & 13.5 & $\mathbf{i}$ & - \\
\hline G2 & $3 F$ & 0.3 & 5.4 & $\mathbf{i}$ & - \\
\hline O2B & $3 F$ & 0.3 & 6.4 & $\mathbf{i}$ & - \\
\hline O2A & $3 F$ & 0.3 & 6.4 & $\mathbf{i}$ & KA6A gen. fall out \\
\hline D2 & $3 F$ & 0.3 & 14.8 & $\mathbf{i}$ & - \\
\hline G1 & $3 F$ & 0.3 & 13.3 & $\mathbf{i}$ & - \\
\hline 01B & $3 F$ & 0.3 & 5.4 & $\mathbf{i}$ & O1B gen., KA6A gen. fall out \\
\hline $01 \mathrm{~A}$ & $3 F$ & 0.3 & 5.3 & $\mathbf{i}$ & O1A gen. fall out \\
\hline D1 & $3 F$ & 0.3 & 14.3 & i & - \\
\hline BU1 & $3 F$ & 0.3 & 1.9 & $\mathbf{i}$ & KA6A gen. fall out \\
\hline BU20 & $3 F$ & 0.3 & 10 & $\mathbf{i}$ & KA6A gen. fall out \\
\hline КА20В & $3 F$ & 0.3 & 2.5 & $\mathrm{i}$ & KA6A gen. fall out \\
\hline KA6B & $3 F$ & 0.3 & 8.5 & $\mathbf{i}$ & KA6A gen. fall out \\
\hline KA6A & $3 F$ & 0.3 & 9.2 & $\mathbf{i}$ & KA6A gen. fall out \\
\hline BU2O & $2 F$ & 0.5 & 5 & $\mathbf{i}$ & - \\
\hline КА20B & $2 F$ & 0.5 & 1.2 & $\mathbf{i}$ & - \\
\hline KA6B & $2 F$ & 0.5 & 6.2 & $\mathbf{i}$ & - \\
\hline KA6A & $2 F$ & 0.5 & 7.2 & $\mathbf{i}$ & - \\
\hline G4 & $3 F$ & 0.3 & 9.5 & o & - \\
\hline $\mathrm{H} 4$ & $3 F$ & 0.3 & 8.6 & 0 & - \\
\hline M4 & $3 F$ & 0.3 & 8.6 & $\circ$ & - \\
\hline $\mathbf{L 4}$ & $3 F$ & 0.3 & 8.2 & $\circ$ & - \\
\hline T4 & $3 F$ & 0.3 & 9.8 & o & - \\
\hline P4 & $3 F$ & 0.3 & 13.5 & o & - \\
\hline G2 & $3 F$ & 0.3 & 5.4 & 0 & - \\
\hline О2B & $3 F$ & 0.3 & 6.4 & 0 & - \\
\hline O2A & $3 F$ & 0.3 & 6.4 & $\circ$ & - \\
\hline D2 & $3 F$ & 0.3 & 14.8 & o & - \\
\hline $400 \mathrm{kV}$ & $220 \mathrm{kV}$ & $120 \mathrm{kV}$ & $20 \mathrm{kV}$ & $6.3 \mathrm{kV}$ & color explanation \\
\hline
\end{tabular}

Table 1.: resuming the simulated faults 
Table 1. shows the sc. currents on different places, and the consequences of the faults: sometimes some of the generators fall out from the synchronism.

\subsection{Results of the simulations}

We want to resume the most important results of the simulations: it is observable, that the generators faults, which work on $400 \mathrm{kV}$, cause greater action to the $6.3 \mathrm{kV}$ generator, but these faults do not cause

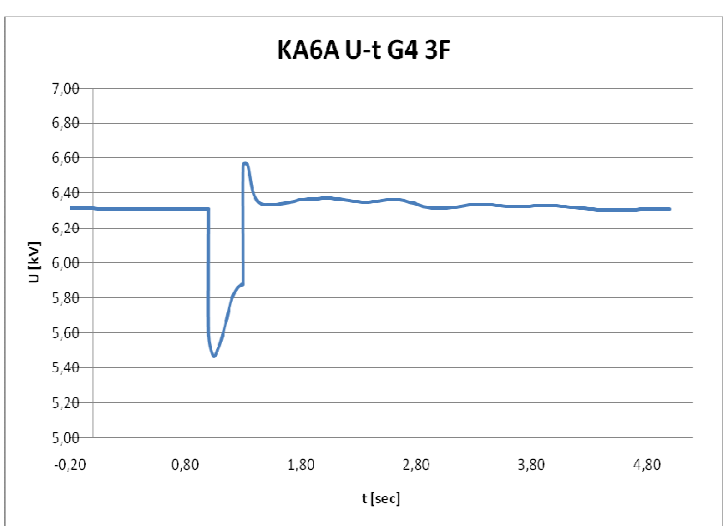

Figure 2.: the KA6A gen. voltage-time chart, the $3 p h$ sc. is on G4 gen.

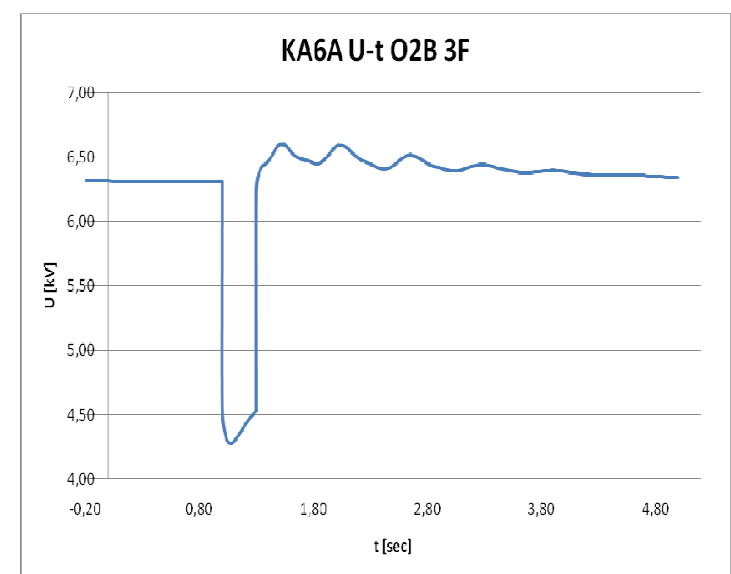

Figure 4.: the KA6A gen. voltage-time chart, the $3 p h$ sc. is on $O 2 B$ gen. outage, the frequency of the generator remains stable. It is perceptible, that the $6.3 \mathrm{kV}$ generator is much more sensitive to the faults in its electrical vicinity.

The other aspect of the analysis, that the MGs can increase the robustness of the network

Comparison was made with and without the $6.3 \mathrm{kV}$-connected generator regarding the stability of generators located to the $120 \mathrm{kV}$ and $20 \mathrm{kV}$ level. It means fault analysis with and without the MG.

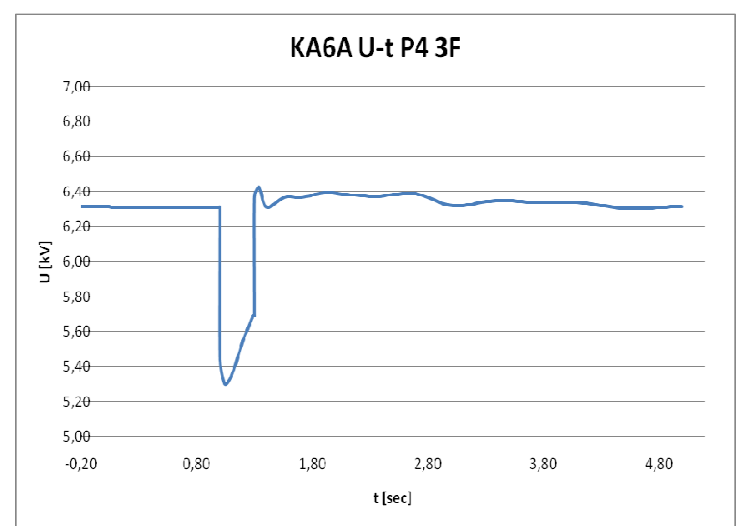

Figure32.: the KA6A gen. voltage-time chart, the 3ph sc. is on P4 gen.

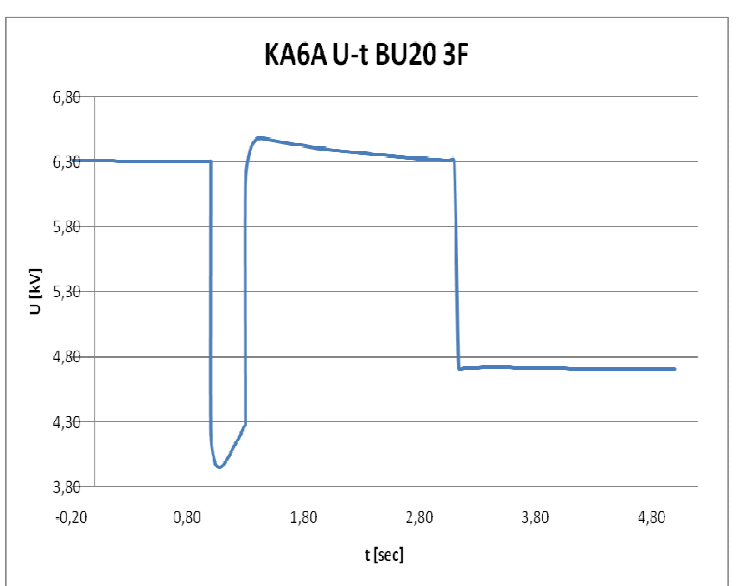

Figure 5.: the KA6A gen. voltage-time chart, the 3ph sc. is on BU20 gen. 
The simulations results show, that the $6.3 \mathrm{kV}$ generator has a so-called voltageimproving ability, so it makes the network more robust.

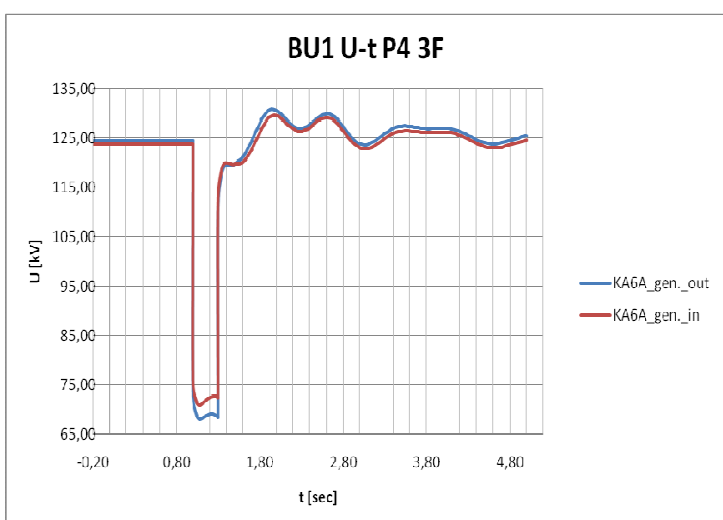

Figure 6.: BU1 voltage-time chart, the 3ph. sc. is on P4 gen. with and without KA6A gen.

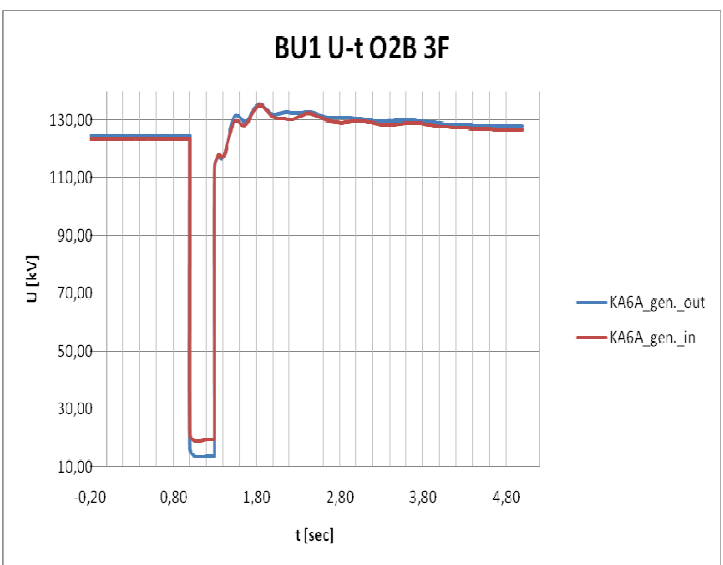

Figure $8 .:$ BU1 voltage-time chart, the $3 p h$. sc. is on O2B gen. with and without KA6A gen.

\section{Conclusion}

The goal of the work was to create a model network, which is able to simulate MGs in a normal high voltage system in a necessary simulator environment. We made a usual system topology, which has normal electric parameters. The used simulator is able to analise system stability. After testing the model a series of measurements were simulated. The results proved the preliminary hypothesis: the MGs increase the robustness of the high voltage transmission system.
It is also to observe, that as closer is the fault to the generator, as larger is the reaction, but the robustness improving ability is larger too.

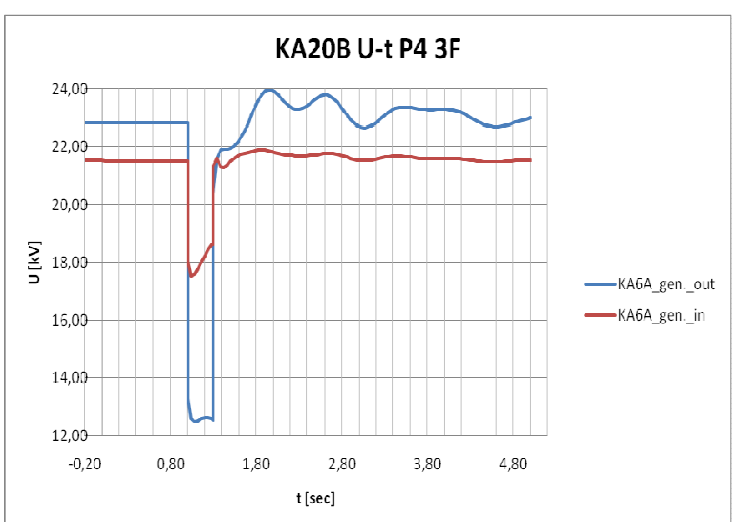

Figure 7.: KA20B voltage-time chart, the 3ph. sc. is on P4 gen. with and without KA6A gen.

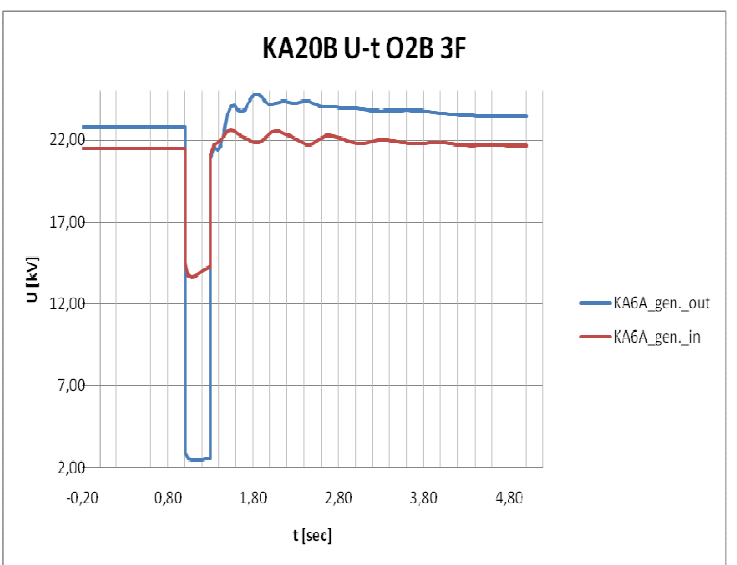

Figure 9.: KA20B voltage-time chart, the $3 p h$. sc. is on $O 2 B$ gen. with and without KA6A gen.

\section{References}

[1] Technical And Economic Feasibility of Micro grid-Based Power Systems

Phil Barker, Doug Herman. Seventh EPRI Distributed Resources Conference and Exhibition Dallas, TX March 20-22, 2002

[2] Daniel Kirschen: Towards Decentralized Power Systems. ECCE meeting in Bruxels, oct. 2003

[3] Khaled A. Nigim, Wei-Jen Lee: Micro Grid Integration Opportunities and Challenges. IEEE 2007 General Meeting, Tampa, USA, 24-28 June 2007

[4] A. Faludi, L. Szabo: Power System Operation and Control (Hungarian) Lecture notes on vet.bme.hu/okt/foszak/ver/veri/index.htm, Budapest 2002 . 